\title{
DE LA SEGURIDAD SOCIAL PARA PREVENIR EL RIESGO DE POBREZA Y EXCLUSION SOCIAL: SU ESPECIAL CONSIDERACION A PERSONAS CON DISCAPACIDAD
}

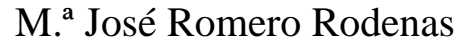 \\ Catedrática de Derecho del Trabajo y Seguridad Social UCLM \\ Catalina Smintinica \\ Profesora Asociada Derecho del Trabajo y Seguridad Social UAM.
}

\begin{abstract}
La emergencia sanitaria ha puesto de manifiesto la necesidad de articular medidas sociales transversales para que tanto las personas como los sectores productivos más vulnerables no queden atrás, apreciándose el riesgo de cronificación y aumento de la pobreza en el futuro si no se actúa con carácter inmediato. Dentro de este escenario nace una nueva renta mínima denominada Ingreso Mínimo Vital, cuyo objetivo es corregir los altos niveles de desigualdad, desempleo no subsidiado y pobreza extrema en España. Estamos ante un nuevo derecho social de carácter subjetivo, ligado al estado de necesidad, cuyo objetivo es prevenir el riego de pobreza y la exclusión social. El presente estudio analiza el ingreso mínimo vital con especial detenimiento en el colectivo con discapacidad.
\end{abstract}

The health emergency has highlighted the need to articulate cross-cutting social measures so that both the most vulnerable people and productive sectors are not left behind, with the risk of timeliness and increased poverty appreciated in the future if not acted immediately. Within this context, a new minimum income called Minimum Vital Income was born, whose objective is to correct the high levels of inequality, unsubsidized unemployment and extreme poverty in Spain. We are facing a new social right of a subjective nature, linked to the state of need, whose objective is to prevent the risk of poverty and social exclusion. This study analyses the minimum living income with special attention to the collective with disabilities.

Title: Minimum Vital Income as a non-contributory Social Security benefit to prevent the risk of poverty and social exclusion: a special consideration for people with disabilities

IUSLabor 2/2021, ISSN 1699-2938, p. 170-197

DOI. 10.31009/IUSLabor.2021.i2.06

Fecha envío: 19.1.2021| Fecha aceptación: 21.4.2021 
Palabras claves: Ingreso Mínimo Vital, Personas con discapacidad, COVID-19, Seguridad Social, Protección Social, renta mínima.

Keywords: Minimum Vital Income, Persons with disabilities, COVID-19, Social Security, Social Protection, Minimum Income.

\section{Sumario}

1. Introducción: fundamento normativo y social

2. El IMV como nueva prestación social

3. Los elementos clave en el diseño normativo del IMV

3.1 Situación de necesidad protegida y naturaleza de la prestación

3.2 Ámbito subjetivo y requisitos de acceso

3.3 Obligaciones de las personas beneficiarias preceptoras del IMV

3.4 Duración y cuantía del IMV

3.5 Financiación y gestión del IMV

4. El IMV y discapacidad una extensa e intensa incompatibilidad

5. Régimen de compatibilidad del IMV con el trabajo

6. Régimen de incompatibilidad del IMV

7. El encaje del IMV con otras prestaciones públicas estatales y autonómicas

8. Bibliografía 


\section{Introducción: fundamento normativo y social}

El estado de emergencia declarado a causa de la crisis sanitaria generada por COVID-19 en España, ha puesto de manifiesto la necesidad de articular medidas sociales transversales para que tanto las personas como los sectores productivos más vulnerables no queden atrás, apreciándose el riesgo de cronificación y aumento de la pobreza en el futuro si no se actúa con carácter inmediato ${ }^{1}$. Dentro de este escenario nace, de forma acelerada pero necesaria, una nueva renta mínima denominada Ingreso Mínimo Vital, cuyo objetivo es corregir los altos niveles de desigualdad, desempleo no subsidiado y pobreza extrema en España, niveles que, hasta ahora, no han podido corregirse plenamente con los modelos autonómicos de rentas mínimas que, además, se han visto agravados por la crisis sanitaria del COVID- $19^{2}$.

El RDL 20/2020, de 29 de mayo, por el que se establece el ingreso mínimo vital (en adelante IMV) personifica un avance objetivo y fundamental en el modelo del Estado Social que la Constitución Española (en lo sucesivo CE) proclama en su artículo 1.1. El IMV es un nuevo derecho social de carácter subjetivo de los ciudadanos españoles y de las personas legalmente residentes en España $^{3}$, ligado al estado de necesidad, "especialmente en caso de desempleo" (artículo $41 \mathrm{CE}$ ).

Las normas supraestatales son de obligada referencia, así, el artículo 11.1 del Pacto Internacional de Derechos Económicos, Sociales y Culturales de 16 de diciembre de 1966, establece que "Los Estados Parte en el presente Pacto reconocen el derecho de toda persona a un nivel de vida adecuado para sí y su familia, incluso alimentación, vestido y vivienda adecuados, y a una mejora continua de las condiciones de existencia". El artículo 13.1 de la Carta Social Europea (revisada) determina que "para garantizar el ejercicio efectivo del derecho a la asistencia social y médica, las Partes se comprometen:

\footnotetext{
${ }^{1}$ En la propia Exposición de Motivos del Real Decreto-ley 20/2020, por el que se establece el ingreso mínimo vital se pone de manifiesto que los motivos que justifican la extraordinaria y urgente necesidad de adoptar la norma reguladora del ingreso mínimo vital vienen constituidos por el impacto económico y social que la crisis sanitaria ocasionada por el COVID-19 está ejerciendo sobre las personas y familias en situación de pobreza y exclusión.

2 "El ingreso mínimo vital se configura como una prestación asistencial (o no contributiva) de Seguridad Social, encomendándose la gestión de la prestación al INSS, salvo en el País Vasco y en Navarra, lo que tarde o temprano conducirá al resto de comunidades autónomas a la asunción (total o parcial) de la gestión de esta prestación (pero sin competencias normativas de desarrollo de la legislación estatal), lo que a la vista de lo que viene sucediendo con las prestaciones de dependencia no aventura nada bueno", Vid. ARRIETA IDIÁKEZ Francisco Javier, "Ingreso Mínimo Vital: compatibilidades e incompatibilidades," en https://forodelabos.blogspot.com/ , 20/7/2020 (https://forodelabos.blogspot.com/2020/07/ingreso-minimovital-compatibilidades-e.html; 22/02/2021).

${ }^{3}$ RAMOS QUINTANA, Margarita Isabel, "El ingreso mínimo vital como instrumento para combatir la pobreza y la exclusión desde el sistema de la Seguridad Social”, Revista Hacienda Canaria, nº 53, 2020, p. 297.
} 
1) a velar por que toda persona que no disponga de recursos suficientes y no esté en condiciones de conseguir éstos por su propio esfuerzo o de recibirlos de otras fuentes, especialmente por vía de prestaciones de un régimen de seguridad social, pueda obtener una asistencia adecuada y, en caso de enfermedad, los cuidados que exija su estado". El artículo 34.3 de la Carta de los Derechos de la UE reza así "Con el fin de combatir la exclusión social y la pobreza, la Unión reconoce y respeta el derecho a una ayuda social y a una ayuda de vivienda para garantizar una existencia digna a todos aquellos que no dispongan de recursos suficientes, según las modalidades establecidas por el Derecho de la Unión y por las legislaciones y prácticas nacionales". El artículo 25.1 de la Declaración Universal de Derechos Humanos de 10 de diciembre de 1948 fija que "Toda persona tiene derecho a un nivel de vida adecuado que le asegure, así como a su familia, la salud y el bienestar, y en especial la alimentación, el vestido, la vivienda, la asistencia médica y los servicios sociales necesarios; tiene asimismo derecho a los seguros en caso de desempleo, enfermedad, invalidez, viudez, vejez y otros casos de pérdida de sus medios de subsistencia por circunstancias independientes de su voluntad". Por último, destacar que el principio 14 del Pilar Europeo de Derechos Sociales está dedicado a la renta mínima, señalando que: "Toda persona que carezca de recursos suficientes tiene derecho a unas prestaciones de renta mínima adecuadas que garanticen una vida digna a lo largo de todas las etapas de la vida, así como el acceso a bienes y servicios de capacitación. Para las personas que pueden trabajar, las prestaciones de renta mínima deben combinarse con incentivos a la (re)integración en el mercado laboral".

Es, justamente, el derecho a la vida el que requiere hoy la introducción de un ingreso o renta mínima vital como su esencial garantía ${ }^{4}$ no solo a nivel estatal sino también con fundamento en normas de ámbito supraestatal.

El nacimiento del IMV constituye un hito histórico, de ahí, la importancia de la configuración del ingreso mínimo vital como prestación no contributiva de la Seguridad Social $^{5}$. Su objetivo principal es garantizar, a través de la satisfacción de unas condiciones materiales mínimas, la participación plena de toda la ciudadanía en la vida social y económica, rompiendo, así, el vínculo entre carencia estructural de recursos y falta de acceso a oportunidades en los ámbitos laboral, educativo o social de los individuos ${ }^{6}$.

El IMV no constituye una política dirigida a grupos o individuos concretos, sino que, atendiendo a aquellos que en un momento determinado sufren situaciones de exclusión y

\footnotetext{
${ }^{4}$ Ferrajoli Luigi, Manifiesto por la igualdad, Madrid, Trotta, 2019, p. 167-184.

${ }^{5}$ Así reza de la Exposición de Motivos RDL 20/2020, 29 de mayo.

6 Monereo PÉrez, José Luis, y Rodríguez InIESTA, Guillermo, "El derecho social fundamental a la existencia digna y el Ingreso Mínimo Vital”, Revista de Derecho de la Seguridad Social, $\mathrm{n}^{\circ}$ 24, 3er Trimestre 2020, p. 19.
} 
vulnerabilidad, protege de forma estructural a la sociedad en su conjunto. Esta política, según queda reflejado en la propia Exposición de Motivos, pretende actuar como un seguro colectivo frente a los retos que nuestras sociedades enfrentaran en el futuro próximo: carreras laborales más inciertas, nuevas vulnerabilidades como la puesta de manifiesto por la crisis de COVID-19, transformaciones económicas asociadas a la robotización o el cambio climático, y en general una mayor volatilidad en los ingresos y los empleos, problemas frente a los que casi nadie será inmune pero que afectaran especialmente a los grupos sociales más vulnerables.

Las personas con discapacidad ${ }^{7}$ representan un colectivo que no solamente se encuentran en situación de vulnerabilidad económica, sino que se encuentran en situación de especial vulnerabilidad, por consiguiente, doble vulnerabilidad, ya que ven impedidas su participación plena y efectiva en la sociedad, en igualdad de condiciones con los demás al presentar deficiencias físicas, mentales, intelectuales o sensoriales. El objetivo del presente trabajo es el análisis del IMV con especial detenimiento en el colectivo con discapacidad y la compatibilidad o incompatibilidad entre la actividad laboral y las prestaciones sociales públicas.

Desde una perspectiva de análisis de la evolución del sistema de Seguridad Social, la creación del $\mathrm{IMV}^{8}$ viene a equilibrar la configuración de un modelo integrado por una doble modalidad, contributiva y no contributiva, siendo esta última hasta ahora un elemento secundario. De ahí la importancia de la configuración del IMV como prestación no contributiva de la Seguridad Social. Es más, a través de la aprobación de este nuevo derecho, España finalmente atiende a las llamadas que desde diversas instituciones europeas ${ }^{9}$ se habían venido haciendo en relación con tomar medidas ante el aumento de

\footnotetext{
${ }^{7}$ El Real Decreto Legislativo 1/2013, de 29 de noviembre, por el que se aprueba el Texto Refundido de la Ley General de derechos de las personas con discapacidad y de su inclusión social, define el concepto de discapacidad (artículo 2.a) y las personas con discapacidad (artículo 4.1).

${ }^{8}$ Sala Franco, Tomás y Martín-POZuelo LóPeZ, Ángela, El Ingreso Mínimo Vital. El Sistema Español de Rentas Mínimas, Valencia, Ed. Tirant Lo Blanch 2020, p. 15.

${ }^{9}$ En este sentido véase la Recomendación del Consejo de 13 de julio de 2018, relativa al Programa Nacional de Reformas de 2018 de España y por la que se emite un dictamen del Consejo sobre el Programa de Estabilidad de 2018 de España (2018/C 320/08), en concreto, su punto 12; la Recomendación del Consejo relativa al Programa Nacional de Reformas de 2019 de España y por la que se emite un dictamen del Consejo sobre el Programa de Estabilidad de 2019 de España COM (2019) 509 final, en concreto el punto 14; Asimismo, el Pilar Europeo de Derecho Sociales, adoptado en la Cumbre Social en favor del empleo justo y el crecimiento celebrada en Gotemburgo en noviembre de 2017, establece veinte principios fundamentales, uno de los cuales, en concreto el principio 14, está dedicado a la renta mínima, señalando «Toda persona que carezca de recursos suficientes tiene derecho a unas prestaciones de renta mínima adecuadas que garanticen una vida digna a lo largo de todas las etapas de la vida, así como el acceso a bienes y servicios de capacitación. Para las personas que pueden trabajar, las prestaciones de renta mínima deben combinarse con incentivos a la (re)integración en el mercado laboral».
} 
los niveles de pobreza y exclusión que desde 2008, a causa de la crisis económica y financiera se habían evidenciado y cumpliendo, de esta manera, con "una exigencia de decencia social" ", especialmente manifestada a causa de la crisis sanitaria generada por COVID-19.

\section{El IMV como nueva prestación social}

El IMV aprobado por el mencionado RDL 20/2020, de 29 de mayo se sitúa en términos jurídicos, económicos y sociales dentro del ámbito de los llamados sistemas de rentas mínimas ${ }^{11}$.

La renta mínima vital o ingreso mínimo vital ${ }^{12}$ es un mecanismo de garantía de ingresos de ámbito nacional ${ }^{13}$, articulado a partir del mandato que el artículo $41 \mathrm{CE}$ otorga al

${ }^{10}$ En relación con el ingreso mínimo vital, APARICIO TOVAR, Joaquín, se pronuncia en el sentido de que "es una exigencia de decencia social", en infoLibre - Información libre e independiente, 09/05/2020. Su opinión al respecto puede consultarse en el siguiente enlace: https://www.infolibre.es/noticias/opinion/plaza_publica/2020/05/09/por_ingreso_minimo_vital_106454_ 2003.html.

${ }^{11}$ Los sistemas de rentas mínimas son considerados la última red de protección de nuestro sistema de protección social, destinadas a las capas más débiles de la población. Por tanto, se dirigen a personas que no podrían alcanzar los ingresos mínimos que garantizarán su subsistencia. Los rasgos determinantes de su estructura son el carácter subsidiario y su naturaleza asistencial. Se trata de prestaciones económicas subordinadas a la constatación de la existencia de situaciones de necesidad probada y a la realización de labores encaminadas a la inserción laboral y social. Los sistemas de rentas mínimas son esencialmente promovidos por las Comunidades Autónomas que se identifican con las rentas mínimas de inserción, sin perjuicio, de la existencia de renta mínima de carácter estatal. Sobre un análisis más profundo sobre rentas mínimas de inserción vid. LALAGUNA HOLZWARTH, Enrique, "Titulares de las rentas mínimas de inserción: perfil de sus beneficiarios y requisitos para su concesión”, en VV.AA., Empleo y exclusión social: rentas mínimas y otros mecanismos de inserción sociolaboral, CARDONA RUBERT, María Belén, (Coord.), Bomarzo, 2008, p. 205-222. Un ejemplo de renta mínima de carácter estatal es el subsidio de desempleo, que sigue vigente hoy día.

${ }^{12}$ Seguimos conceptualmente la terminología que FERRAJOLI utiliza del término renta y distingue dos tipos de renta básica garantizada: "la renta mínima garantizada solo a los necesitados previa comprobación de la carencia de una renta suficiente para sobrevivir y/o de otras condiciones" sería nuestro IMV y, en cambio, "la conferida a todos como objeto de un derecho fundamental, y por eso universal "sería la Renta Mínima Universal no está regulada en nuestro ordenamiento jurídico. FERRAJOLI Luigi, Manifiesto por la igualdad...op.cit. p. 168.

${ }^{13}$ En España, el IMV al ser de carácter estatal supone una novedad en tanto en cuanto la situación de necesidad a la que pretende dar cobertura ya viene contemplada, aunque con una escasa cobertura por las Comunidades Autónomas a través de las denominadas rentas mínimas de inserción. De hecho, esta nueva prestación presenta muchas similitudes con las rentas mínimas de inserción tanto en objetivo como en beneficiarios pero, se diferencian en que las rentas mínimas de inserción se fundamentan en la competencia exclusiva sobre la asistencia social contemplada en el artículo 148.1.20 de la Constitución Española que la otorga a las Comunidades Autónomas mientras que el ingreso mínimo vital es una nueva prestación de la Seguridad Social donde el Estado tiene competencias para intervenir (ex. Artículo 2.2 RDL 20/2020 al citar 
régimen público de la Seguridad Social para garantizar la asistencia y prestaciones suficientes, no mínimas ${ }^{14}$, ante situaciones de necesidad, que asegura un determinado nivel de rentas a todas las personas y hogares en situación de vulnerabilidad con independencia del lugar de residencia.

Se trata de una nueva prestación de Seguridad Social no contributiva y, por tanto, inserta en el sistema institucional de la Seguridad Social ${ }^{15}$. Esta consideración permite como primera idea-fuerza que, con su aprobación, España avanza hacia un modelo de país más integrador basado en el desarrollo y la inclusión social ${ }^{16}$.

Se diferencia de una renta básica incondicionada como derecho de ciudadanía plena ${ }^{17}$ y sin exigencia de acreditar una situación de necesidad. El IMV responde a un modelo de renta mínima ${ }^{18}$ basado en la solidaridad social que exige de la comprobación de recursos del beneficiario individual o de la unidad de convivencia y condicionado a una situación de necesidad, esto es, vulnerabilidad económica que impida la satisfacción de necesidades básicas para el gozo de una vida digna. El IMV, aunque podría entenderse como una prestación familiar al cubrir situaciones de vulnerabilidad económica de las denominadas

el propio artículo $41 \mathrm{CE}$ ) fundamentándose en el artículo 149.117 de la carta magna, esto es, la competencia estatal en materia de Seguridad Social.

${ }^{14}$ El artículo 41 de la CE expresa claramente un principio de suficiencia de las prestaciones y no habla de mínimos con el fin de asegurar unas prestaciones decentes, que son las necesarias para el goce de los derechos. Vid. APARICIO TOVAR, Joaquín, "La sostenibilidad como excusa para una reestructuración del sistema de la Seguridad Social”, Cuadernos de Relaciones Laborales, Vol. 33, nº 2, 2015, p. 297.

${ }^{15}$ Las prestaciones no contributivas de Seguridad Social atienden esencialmente tres contingencias: la invalidez, la jubilación y las cargas familiares. No obstante, la ordenación legal recoge también prestaciones en forma de subsidio para algunas situaciones más específicas como el nacimiento de hijo (artículos 181 y 182 TRLGSS) y el desempleo (artículos 274 y ss. TRLGSS).

16 Ramos QUINTANA, Margarita Isabel, "El ingreso mínimo vital como instrumento para combatir la pobreza y la exclusión desde el sistema de la Seguridad Social”, op.cit., p. 298.

${ }^{17}$ La renta básica universal se configura como un ingreso pagado por el Estado a cada miembro de pleno derecho de la sociedad con independencia de su condición de activo o de pasivo y con independencia de que disponga de otras fuentes de renta. Para una información más amplia de la renta básica universal vid. LEGARRETA Esteban, Ricardo, "La renta básica universal", en VV.AA., "Políticas sociolaborales", CArdona Rubert, María Belén, (coord.), CABeza Pereiro, Jaime, (coord.), Navarra, Ed. Thomson Reuters-Civitas, 2014, p. 559-567. granadia Elena., bolzoni Magda, Il reddito di base, Roma, Ediesse, 2016, p. 16. FERRAJOLI Luigi: Manifiesto por la igualdad... op.cit. p. 168 y ss.

${ }^{18}$ Por razones políticas y económicas en el recorrido institucional español se opta por un modelo de renta mínima en lugar de un modelo de renta universal. Esta última opción supondría un elevado compromiso y coste económico para las arcas públicas. Es por ello por lo que se opta por una renta que pretende asegurar un mínimo a la ciudadanía, pero condicionado a la existencia de una situación de vulnerabilidad económica o social y al cumplimiento de determinados requisitos. Se concibe como elemento complementario de la acción protectora del sistema, tratando de cubrir y atender necesidades de la población a las que el propio sistema no alcanza mediante su estructura prestacional tradicional. 
"unidades de convivencia", su ámbito subjetivo es más amplio al atender también a situaciones individuales (artículos 4 y ss., del RDL 20/2020).

Para una efectiva implementación del IMV se evidenció la necesidad de tomar medidas con carácter inmediato, lo cual ha motivado que el RDL 20/2020, de 29 de mayo, sea objeto de modificaciones en un breve lapso de tiempo desde su entrada en vigor. En primer lugar, el RDL 25/2020, de 2 de julio, introdujo modificaciones con el fin de facilitar el modelo de gestión y gobernanza del ingreso mínimo vital en las Comunidades Autónomas con Haciendas Forales (País Vasco y Navarra). En un segundo momento, a través del RDL 28/2020, de 22 de septiembre, que regula el trabajo a distancia, introduce modificaciones de más calado con el fin de dar cobertura al mayor número de personas en el menor tiempo posible. El RDL 30/2020, de 29 de septiembre, de medidas sociales en defensa del empleo, se completa la "reforma imprescindible" quedando corregidos aquellos puntos oscuros de la norma que provocaban inseguridad jurídica y aquellos otros que obligaban a desestimar el reconocimiento de las prestaciones, causando la desprotección de aquellos que son acreedores de estas ${ }^{19}$. El RDL 35/2020, de 22 de diciembre, de medidas urgentes de apoyo al sector turístico, la hostelería y el comercio y en materia tributaria, modifica el artículo 29 relativo a los mecanismos de colaboración del IMV con otras administraciones. También mencionar, el Real Decreto-ley 39/2020, de 29 de diciembre, de medidas financieras de apoyo social y económico y de cumplimiento de la ejecución de sentencias que establece una reducción de la fiscalidad de los beneficiarios del Ingreso Mínimo Vital. En concreto, esta prestación concedida a los colectivos más vulnerables queda exenta en el IRPF en los mismos términos que las prestaciones económicas establecidas por las Comunidades Autónomas en concepto de renta mínima de inserción, así como las demás ayudas establecidas por las comunidades o las Entidades Locales para garantizar recursos económicos de subsistencia a las personas que carezcan de ellos o se encuentren en riesgo de exclusión social. De este modo, el Ingreso Mínimo Vital junto con dichas prestaciones y ayudas se consideran exentas del IRPF hasta un importe máximo anual conjunto de 1,5 veces el indicador público de rentas de efectos múltiples (IPREM). Y, por último, destacamos las modificaciones introducidas por el artículo 3 del Real Decreto-ley 3/2021, de 2 de febrero, por el que se adoptan medidas para la reducción de la brecha de género y otras materias

\footnotetext{
${ }^{19}$ En la entrevista concedida el pasado 21 de octubre de 2020, el Personal técnico del Ministerio de Inclusión, Seguridad Social y Migraciones da respuestas a las principales dudas planteadas sobre la renta mínima vital. Manifiesta que el principal motivo por el cual se deniegan las prestaciones es por el incumplimiento de los requisitos de vulnerabilidad económica, porque las personas solicitantes exceden los umbrales de renta y/o patrimonios establecidos para poder ser preceptores de la renta mínima. El segundo motivo de denegación era no estar inscrito como demandante de empleo como exigía la norma y que posteriormente se ha modificado y convertido en una obligación de cumplimiento a posteriori. https://elderecho.com/, 21/10/2020. El contenido puede consultarse en el siguiente enlace: https://elderecho.com/la-10-respuestas-clave-a-una-tramitacion-mas-accesible-del-ingreso-minimo-vital .
} 
en los ámbitos de la Seguridad Social y económico, relativas al ámbito subjetivo de aplicación, a la acción protectora y al procedimiento de acceso al ingreso mínimo vital. Los cambios principales consisten en la ampliación de la capacidad de ser beneficiario de la renta mínima vital al extenderse a las personas que residan en establecimientos financiados con fondos privados, así como, en la eliminación del límite de titulares del IMV en un mismo domicilio. Se flexibiliza el concepto de unidad de convivencia para que un mayor número de hogares puedan acceder a la prestación. En este sentido, en casos especiales de empadronamiento en establecimientos colectivos, el empadronamiento en infraviviendas y de personas sin domicilio, se permitirá que la unidad de convivencia se configure por el titular, por las personas unidas entre sí por vínculo matrimonial, como pareja de hecho, y, en su caso, con sus descendientes menores de edad hasta el primer grado de consanguinidad, afinidad, adopción o en virtud de régimen de acogimiento familiar permanente o guarda con fines de adopción. Todo ello, hace necesario la modificación del procedimiento para ampliar y agilizar la participación en la Comisión de seguimiento y en el Consejo Consultivo del IMV de otros representantes de la Administración General del Estado.

Todo el conjunto de modificaciones legales en tan corto espacio de tiempo nace con la vocación de dar seguridad jurídica y perfilar los obstáculos e interpretaciones de una regulación normativa técnicamente rápida y con aristas importantes, vacíos legales a espera del reglamento del IMV.

\section{Los elementos clave en el diseño normativo del IMV}

Los elementos clave se centran en: la situación de necesidad protegida y naturaleza de la prestación; el ámbito subjetivo y requisitos de acceso; las obligaciones de los beneficiarios de la renta mínima vital; la duración y cuantía de la renta mínima vital y, por último, pero no menos importante, la financiación y gestión de la renta mínima vital.

\subsection{Situación de necesidad protegida y naturaleza de la prestación}

La renta mínima vital es una prestación dirigida a prevenir el riesgo de pobreza y exclusión social de las personas que vivan solas o integradas en una unidad de convivencia por carecer de recursos económicos suficientes para la cobertura de sus necesidades básicas (artículo 1). Esto es, estamos ante una "renta garantizada" por el propio sistema de Seguridad Social, cuya naturaleza asistencial y no contributiva, pretende asegurar unos ingresos mínimos a aquellos sujetos protegidos que carecen de ellos. Su propia naturaleza no contributiva implica que la duración de la situación 
protegida quede condicionada mientras la situación de necesidad económica persista, así como, los requisitos de acceso a esta, para conservar el derecho al ingreso mínimo ${ }^{20}$.

Además, se configura como una red de protección encaminada a cubrir el tránsito desde la situación de exclusión a la de participación social. En consecuencia, no se trata de una prestación que nace con vocación de permanencia sino de transitoriedad, dado que, su objetivo es facilitar que aquellos sujetos que se encuentren en situaciones económicas desfavorables puedan salir de ellas e integrarse activamente en la sociedad. La protección del IMV se articula diferenciando si va dirigida a un beneficiario individual o a una unidad de convivencia.

El artículo 2 RDL 20/2020, indica que la renta mínima vital habrá de garantizar un nivel mínimo de rentas a quienes se encuentren en situación de vulnerabilidad económica, que a efectos de esta prestación constituye la situación protegida. La cuestión es determinar cuándo se considera que existe esa situación de necesidad o ausencia de capacidad económica. En este sentido, el artículo 8 del RDL 20/2020, dispone que concurre la ausencia de capacidad económica o la vulnerabilidad económica cuando el promedio mensual del conjunto de ingresos y rentas anuales computables de la persona beneficiaria (individual o del conjunto de miembros) correspondientes al ejercicio fiscal anterior, sea inferior, al menos en 10 euros, a la cuantía mensual de la renta garantizada con esta prestación que corresponda en función de la modalidad y del número de miembros de la unidad de convivencia (según la escala prevista en el anexo I de la misma ley).

Existen dos excepciones en las que, aun cumpliendo ese parámetro, no se considerará que existe vulnerabilidad económica. Esto es, cuando el beneficiario sea administrador de derecho de una sociedad mercantil que no haya cesado en su actividad y, en función del patrimonio. Para determinar el valor del patrimonio, en el caso del beneficiario individual se tomará en consideración un importe igual o superior a tres veces la cuantía correspondiente de renta garantizada por el mínimo vital (16.614 euros para 2020). Y, en el caso de los miembros de la unidad familiar, se tomará en consideración la escala del Anexo II del RDL 20/2020 para determinar el patrimonio como umbral a acceder a la prestación. El computo de los ingresos y patrimonio se realizará atendiendo a las reglas del artículo 18 del RDL 20/2020.

\footnotetext{
20 Se trata de un rasgo común de las prestaciones no contributivas. Lo característico del nivel no contributivo es que la protección social se justifica por la carencia efectiva de recursos económicos del sujeto protegido, que ha de ser acreditada o probada. La carencia de recursos hace que la situación protegida sea, en alguna medida, provisional o inestable, en la medida en que ha de mantenerse a lo largo del disfrute de la prestación para conservar el derecho a esta.
} 


\section{2. Ámbito subjetivo y requisitos de acceso}

Anteriormente, se ha mencionado que, la protección del IMV se articula diferenciando si se trata de un beneficiario individual o de una unidad de convivencia. Esta dualidad persiste cuando se trata de definir al sujeto beneficiario de esta prestación no contributiva.

A tenor del artículo 4 del RDL 20/2020, se contemplan dos tipos de personas beneficiarias: las personas que se encuentren en situación de vulnerabilidad económica y están dentro de una unidad de convivencia y las personas de al menos 23 años y menores de 65 años o mayores de dicha edad cuando no sean beneficiarios de pensión de jubilación, que viven solas o que, compartiendo domicilio con una unidad de convivencia no se integran en la misma, siempre que concurran las circunstancias establecida por la norma.

El artículo 6.1 del RDL 20/2020 ${ }^{21}$, se refiere a una unidad de convivencia como la constituida por todas las personas que residan en un mismo domicilio y que estén unidas entre sí por vinculo de matrimonio o como pareja de hecho o por vínculo hasta el segundo grado de consanguinidad, afinidad, adopción, y otras personas con las que convivan en virtud de guarda con fines de adopción o acogimiento familiar permanente ${ }^{22}$. El último cambio legislativo en la materia ha modificado el concepto de convivencia en el sentido de permitir contemplar como unidad de convivencia independiente situaciones que afectan a los potenciales beneficiarios del IMV, como, por ejemplo, residir en un domicilio con personas con las que tuvieran vínculos propios de la unidad de convivencia, pero cuya convivencia se deba a una situación especial. Esta consideración de unidad de convivencia independiente tendrá carácter temporal, salvo en el caso de las mujeres víctimas de violencia de género.

En caso de ser beneficiario individual (artículo 4.1 b) RDL 20/2020), la edad mínima de la persona titular será de 23 años, salvo los supuestos de mujeres víctimas de violencia de género o de trata de seres humanos y explotación sexual, en los que se exigirá que la persona titular sea mayor de edad.

\footnotetext{
${ }^{21}$ El RD-Ley 3/2021, de 2 de febrero, por el que se adoptan medidas para la reducción de la brecha de género y otras materias en los ámbitos de la Seguridad Social y económico, introduce nuevas modificaciones en relación con el concepto de unidad de convivencia, incluyendo al art 6 los 6 bis, 6 ter y 6 quater, a fin de flexibilizar el mismo y, así, permitir que un mayor número de hogares puedan acceder a la prestación.

${ }^{22}$ Vid. Resolución de 29 de abril de 2020 de la Subsecretaría, por la que se publica la Resolución de 17 de febrero de 2020, de la Presidencia del Instituto Nacional de Estadística y de la Dirección General de Cooperación Autonómica y Local, por la que se dictan instrucciones técnicas a los Ayuntamientos sobre la gestión del Padrón municipal, BOE-A-2020-4784.
} 
Los extranjeros también podrán ser sujetos titulares de esta prestación de acuerdo con el artículo 19 relativo a la acreditación de los requisitos "La residencia legal en España se acreditará mediante la inscripción en el registro central de extranjeros, en el caso de nacionales de los Estados miembros de la Unión Europea, Espacio Económico Europeo o la Confederación Suiza, o con tarjeta de familiar de ciudadano de la Unión o autorización de residencia, en cualquiera de sus modalidades, en el caso de extranjeros de otra nacionalidad".

Con carácter general, inicialmente, la ley excluía como beneficiarios del ingreso mínimo vital, las personas usuarias de una prestación de servicio residencial, de carácter social, sanitario o sociosanitario, con carácter permanente y financiada con fondos públicos. No obstante, en la actualidad sí que son reconocidos como beneficiarios de esta prestación. ${ }^{23}$.

En su momento, la exclusión automática de las personas que tenían su capacidad modificada judicialmente generó una polémica que hizo necesario clarificar e interpretar el artículo 5 del RD-ley 20/2020, ${ }^{24}$ al establecer como titulares de esta prestación a las personas con plena capacidad de obrar que la soliciten y la perciban, en nombre propio o en nombre de una unidad de convivencia. En este sentido, destacar el oficio dictado por el Director General de Ordenación de la Seguridad Social, a través del cual se reconoce que las personas con capacidad modificada judicialmente podrán percibir el IMV. Esta reivindicación partía de que la redacción inicial del decreto-ley suponía una "exclusión de facto" y "una discriminación" para un sector de la población en grave riesgo de exclusión, que afectaba directamente a muchas personas con discapacidad. Los representantes legales de estas personas podrán solicitar dicha ayuda en su nombre, para "evitar la desatención" de dicho colectivo y corregir una "discriminación injustificable" 25 .

\footnotetext{
${ }^{23}$ Una vez más, recién modificado mediante el RD-Ley 3/2021, de 2 de febrero, por el que se adoptan medidas para la reducción de la brecha de género y otras materias en los ámbitos de la Seguridad Social y económico, en el sentido de que se amplía la prestación a las personas que residan en establecimientos financiados con fondos privados, dado que en la redacción anterior se extendía a establecimientos públicos. ${ }^{24}$ Este artículo fue modificado tanto por la Disposición Final Quinta del Real Decreto-ley 30/2020 como por el RD-Ley 3/2021. Mediante la última modificación, se suprime el límite de titulares de IMV en un mismo domicilio, constituido hasta ahora por un número de dos. Con esta medida se pretende eliminar las barreras de acceso a la prestación de las personas usuarias de prestaciones de servicio residencia y reconocer la realidad de las personas que se agrupan en una misma vivienda con el fin exclusivo de compartir gastos. ${ }^{25}$ Las personas cuya capacidad de obrar ha sido modificada judicialmente podrán percibir el Ingreso Mínimo Vital (IMV) aunque vivan solas o con un cuidador con el que no mantienen parentesco cercano, según un oficio dictado por el director General de Ordenación de la Seguridad Social, Borja Suárez, en respuesta a una petición del Comité Español de Representantes de Personas con Discapacidad (CERMI). https://plenainclusionmadrid.org/, 22/07/2020. Vid. https://plenainclusionmadrid.org/noticias/ingresominimo-vital-personas-incapacitadas-judicialmente.
} 
Para acceder al IMV es necesario que se acrediten los requisitos legalmente exigidos, porque se trata de una medida condicionada a un déficit de recursos económicos del sujeto o de la unidad de convivencia. Los requisitos exigidos por el RDL 20/2020, deberán cumplirse tanto para acceder a esta nueva prestación como para mantener su percibo.

Además de los requisitos relativos a la edad, para acceder al IMV se requiere, de acuerdo con el artículo 7 de la disposición legal, haber residido de forma legal e ininterrumpida en España durante al menos el año anterior a la presentación de la solicitud. El requisito de residencia legal y efectiva en España es una cautela muy común en este tipo de prestaciones, ya que trata de evitar que personas que carecen de vínculo con la comunidad puedan acceder a este tipo de prestaciones. Esta exigencia legal no se considerará incumplida en el caso de que el beneficiario se haya ausentado del territorio español por un periodo no superior a noventa días naturales dentro del año natural, o cuando dicha ausencia esté motivada por causas de enfermedad debidamente justificadas.

No obstante, el plazo de un año no se exigirá a los menores incorporados a la unidad de convivencia por nacimiento, adopción, guarda con fines de adopción o acogimiento familiar permanente, como tampoco a las víctimas de trata de seres humanos y de explotación sexual y a las mujeres víctimas de violencia de genero.

Otro requisito, elemento sustantivo de la prestación, es encontrarse en situación de vulnerabilidad económica por carecer de rentas, ingresos o patrimonio suficientes y haber solicitado las pensiones y prestaciones a las que pudiera tener derecho. Quedan exceptuados los salarios sociales, rentas mínimas e inserción o ayudas análogas de asistencia social concedidas por las Comunidades Autónomas ${ }^{26}$. Para los beneficiarios individuales, no integrados en una unidad de convivencia, se exige acreditar haber vivido durante al menos tres años previos a la solicitud de forma independiente de los progenitores y haber cotizado al menos durante 12 meses a la Seguridad Social y figurar inscritos como demandantes de empleo ${ }^{27}$.

\footnotetext{
${ }^{26}$ Es sorprendente la compatibilidad absoluta entre las prestaciones autonómicas de renta mínima y el IMV, en especial, si se tiene en cuenta que esta nueva prestación tiene la misma naturaleza que las rentas mínimas autonómicas. Quizás, los fondos autonómicos destinados hasta el momento a sufragar el gasto de las prestaciones autonómicas pasen a convertirse en un complemento o mejora del IMV en la cuantía que decida cada CCAA. Al respecto, vid. GONZÁLEZ ORTEGA, Santiago y BARCELÓN COBEDO, Susana, "La acción protectora del Sistema de Seguridad Social (I): el nivel no contributivo de prestaciones. El nivel contributivo o profesional: la protección de las situaciones de embarazo, parto y posparto y del desempleo", Introducción al Derecho de la Seguridad Social, Valencia, Tirant lo Blanch, 2020, p. 275-276.

${ }^{27}$ En la reforma llevada a cabo mediante la Disposición Final Undécima del RDL 28/2020, de 22 de septiembre, de trabajo a distancia, se modifica el RDL 20/2020, de 29 de mayo, por el que se establece el ingreso mínimo vital, se ha suprimido la obligatoriedad de estar inscrito antes de realizar la solicitud. Se da un plazo de 6 meses para que el solicitante de la prestación se inscriba como demandante de empleo.
} 


\subsection{Obligaciones de las personas beneficiarias preceptoras del IMV}

Durante la percepción del IMV, los titulares deberán cumplir con las obligaciones establecidas al efecto para poder continuar ser perceptores del ingreso. En concreto, las obligaciones están enumeradas en el artículo 33 del RDL 20/2020, modificado por la Disposición Final Undécima del Real Decreto-ley 28/2020, de 23 de septiembre. Se añade el artículo 33 bis por el artículo3.13 del RD-ley 3/2021, de 2 de febrero, que establece la obligación del Ayuntamiento de comunicar al Instituto Nacional de la Seguridad Social los cambios en el padrón, dentro de los treinta días siguientes a que se produzcan.

Se establecen como obligaciones: a) proporcionar la documentación e información precisa en orden a la acreditación de los requisitos y la conservación de la prestación y garantizar la recepción de notificaciones y comunicaciones; b) comunicar, en el plazo de 30 días naturales, cualquier cambio o situación que pudiera dar lugar a la modificación, suspensión o extinción de la prestación; c) comunicar, en el plazo de 30 días naturales, cualquier cambio de domicilio o situación en el Padrón municipal que afecte personalmente a dichos titulares o a cualquier otro miembro que forme parte de la unidad de convivencia; d) reintegrar el importe de las prestaciones indebidamente percibidas; e) con carácter previo, comunicar a la entidad gestora las salidas al extranjero, tanto del titular como de los miembros de la unidad de convivencia y, en su caso, justificar la ausencia del territorio español; f) presentar anualmente la declaración correspondiente al Impuesto sobre la Renta de las Personas Físicas; g) las personas mayores de edad o menores emancipados, si no están trabajando, deberán acreditar, dentro de los seis meses siguientes a la notificación de la resolución por la que se concede la prestación, que figuran inscritas como demandantes de empleo.

Se establecen excepciones a esta obligación, en los siguientes casos: en primer lugar, ser menor de 28 años y estar cursando estudios reglados. En este caso, el plazo de seis meses, para acreditar la inscripción como demandante de empleo, se iniciará en la fecha en que el beneficiario cumpla 28 años de edad. En segundo lugar, tener suscrito el convenio especial regulado en el Real Decreto 615/2007, de 11 de mayo, por el que se regula la Seguridad Social de los cuidadores de las personas en situación de dependencia. En tercer lugar, estar percibiendo una pensión contributiva de incapacidad permanente en grado de absoluta o gran invalidez, una pensión de invalidez no contributiva o una pensión de jubilación contributiva o haber cumplido los 65 años de edad. En cuarto lugar, estar afectado por una discapacidad en un grado igual o superior al 65 por ciento. Y, por último, tener reconocida una situación de dependencia, conforme a lo dispuesto en la Ley 39/2006, de 14 de diciembre, de Promoción de la Autonomía Personal y Atención a las personas de dependencia. 
La situación de demandante de empleo quedará acreditada con el documento expedido al efecto por la administración competente o mediante el acceso por parte de la entidad gestora a través de los medios electrónicos habilitados al efecto.

Igualmente, en caso de compatibilizar la prestación de renta mínima vital con las rentas de trabajo o la actividad económica conforme al artículo 8.4, es necesario que se cumplan las condiciones establecidas para el acceso y mantenimiento de dicha compatibilidad. Se establece como obligación para seguir siendo beneficiario de esta prestación, participar en las estrategias de inclusión que promueva el Ministerio de Inclusión, Seguridad Social y Migraciones, previstas en el artículo 28.1. Y, por último, se dispone que se pueda requerir el cumplimiento de cualquier otra obligación que pueda establecerse reglamentariamente.

De las modificaciones realizadas destacamos que la inscripción como demandante de empleo se convierte de un requisito de acceso a una obligación que se pueda cumplir a posteriori, en concreto, en el plazo de los seis meses desde la resolución favorable de la solicitud del IMV.

\subsection{Duración y cuantía del IMV}

Uno de los elementos sustantivos del IMV es que es una prestación cuya duración se prolongará mientras persista la situación de vulnerabilidad económica y se mantengan los requisitos que originaron el derecho a su percepción. La duración es potencialmente indefinida atendiendo a la duración o superación de la situación de necesidad objeto de cobertura. En caso de que se supere la situación de necesidad fijada en el nivel mínimo de rentas legalmente establecido, desparecerá el presupuesto de hecho de la norma y se extinguirá el derecho a la percepción de la prestación, sin perjuicio de que las personas puedan solicitar nuevamente ese derecho si vuelven a encontrarse en situación de necesidad.

En cuanto a la determinación de la cuantía mensual de la prestación del IMV que corresponde a la persona individual o a la unidad de convivencia vendrá determinada por la diferencia entre la cuantía de la renta garantizada y el conjunto de todas las rentas e ingresos de la persona beneficiaria o de los miembros que componen esa unidad de convivencia del ejercicio anterior, en los términos establecidos en los artículos 8,13 y 17, siempre que la cuantía resultante sea igual o superior a 10 euros mensuales, de conformidad con el artículo 10. Se establecen dos casos especiales: cuando los hijos o mayores incapacitados judicialmente formen parte de distintas unidades familiares en supuestos de custodia compartida establecida judicialmente, se considerará, a efectos de la determinación de la cuantía de la prestación que forman parte de la unidad donde se 
encuentren domiciliados; reglamentariamente se determinara el posible incremento de las cuantías cuando se acrediten gastos de alquiler de la vivienda habitual superiores al $10 \%$ de la renta garantizada que corresponda, en su cuantía anual.

\subsection{Financiación y gestión del IMV}

De acuerdo con el Capítulo VI del RDL 20/2020, la financiación es íntegramente estatal con cargo a los presupuestos generales del Estado. Es cierto que la financiación del IMV ha generado un aluvión de críticas, en tanto en cuanto esta prestación, aunque necesaria se une a un sistema de Seguridad Social sobrecargado económicamente, deficitario, falto de ingresos ${ }^{28}$. No obstante, la necesidad de reforzar el sistema de protección social y de aportar soluciones es absolutamente imperiosa, ya que los actuales instrumentos de protección social son insuficientes ${ }^{29}$ para proteger a todas las personas que se encuentran en situación de necesidad. La protección de las personas con escasa o ninguna cobertura social pública es una exigencia social, cívica y democrática ${ }^{30}$.

Su gestión es pública y residenciada en el Instituto Nacional de la Seguridad Social (INSS) para garantizar su homogeneidad al igual que las demás prestaciones del sistema de Seguridad Social, sin perjuicio de la colaboración en la gestión por parte de las Comunidades Autónomas. Más recientemente a través de la Disposición Final Quinta del RD-ley 35/2020, de 22 de diciembre, de medidas urgentes de apoyo al sector turístico, la hostelería y el comercio y en materia tributaria se modifica el artículo 29 del RDL 20/2020 en el sentido de una mayor intensificación en las relaciones de cooperación, para mejorar la eficiencia de la gestión de la prestación no contributiva de ingreso mínimo vital, así como facilitar la utilización conjunta de medios y servicios públicos, mediante la asistencia recíproca y el intercambio de información, el Ministerio de Inclusión, Seguridad Social y Migraciones o, en su caso, la Administración de la Seguridad Social podrán celebrar los oportunos convenios, o acuerdos, o cualquier otro instrumento de

\footnotetext{
${ }^{28}$ Vid. GALA DURAN, Carolina, "Los desafíos del nuevo ingreso mínimo vital”, IUSLabor. Revista d'anàlisi de Dret del Treball, $\mathrm{n}^{\circ} 2,2020$.

${ }^{29}$ En la Exposición de Motivos de la iniciativa legislativa popular sobre establecimiento de una prestación de ingresos mínimos en el ámbito de protección de la Seguridad Social, se ha puesto de manifiesto que "Mientras que las prestaciones por desempleo sólo protegen al 55,7\% de las trabajadoras y de los trabajadores desempleados y con una cobertura de carácter temporal, en el ámbito de protección que se ofrece desde otras administraciones públicas que proporcionan las rentas mínimas de inserción, se refleja una tasa de cobertura en la totalidad del Estado que apenas supera la cifra del 5,48\%. Dentro del ámbito de la Seguridad Social, las prestaciones por hijo a cargo son manifiestamente insuficientes para aliviar mínimamente la pobreza infantil".

${ }^{30}$ Monereo Pérez, José Luis, y RodríGuez InIESTA, Guillermo, "El derecho social fundamental a la existencia digna y el Ingreso Mínimo Vital", Revista de Derecho de la Seguridad Social, $\mathrm{n}^{\circ}$ 24, 3er Trimestre 2020, p. 16.
} 
colaboración con otros órganos de la Administración General del Estado, de las administraciones de las comunidades autónomas y de las entidades locales.

El modelo de gobernanza compartido, en el cual de forma articulada y coordinada participan las Comunidades Autónomas y las Entidades Locales, persigue un doble objetivo. En primer lugar, lograr un despliegue más efectivo de la política de cara al ciudadano. La evaluación de los programas de sostenimiento de rentas ha identificado como uno de los problemas recurrentes el hecho de que muchos de sus potenciales beneficiarios acaban no acceder a ellos bien por la complejidad de los procedimientos, la naturaleza de los colectivos a los que va dirigido, o una combinación de ambos. Con la implicación de las Comunidades Autónomas y Entidades Locales, a través de los servicios sociales, se busca maximizar para llegar por diferentes canales a todos los posibles solicitantes, con el objeto de minimizar los problemas de acceso a la política pública. Y, en segundo lugar, la implicación de las Comunidades Autónomas y Entidades Locales en el despliegue de la política persigue consolidar la necesaria implicación de todas las instituciones en el compromiso común de lucha conta la pobreza y las desigualdades en todo el territorio.

De forma que el INSS será el organismo competente para el reconocimiento y control de la prestación, sin perjuicio de la posibilidad de suscribir los convenios señalados.

\section{EI IMV y discapacidad: una extensa e intensa incompatibilidad}

La protección de las personas con discapacidad en el sistema de Seguridad Social se realiza mediante ambas modalidades de protección (no contributiva y contributiva), si bien, sus requisitos para el acceso a las prestaciones contributivas supone un auténtico hándicap para las personas con discapacidad precisamente por no alcanzar la cotización suficiente para causar derecho a una prestación de carácter contributivo al exigirse los mismos requisitos de acceso y contribución al sistema de Seguridad Social en su modalidad contributiva. A ello se debe que el sistema y la práctica permite que la percepción de rentas mínimas (CCAA) o IMV en la actualidad pueda servir como un instrumento que desincentive bien el mantenimiento del empleo, bien la búsqueda activa de empleo de las personas con discapacidad, son muchos los factores de tal afirmación pero el más fundado es la articulación de incompatibilidades férreas en nuestro sistema normativo de prestaciones con el desempeño de cualquier actividad laboral y/o limitación de rentas. El artículo 8.4 RDL 20/2020 fija determinadas condiciones que permitan la compatibilidad entre el IMV y el trabajo, que analizaremos posteriormente y que constituye a nuestro juicio una regulación acertada que mitiga los efectos negativos relativos con el desarrollo de una actividad laboral o búsqueda activa de empleo. 
El subsidio de garantía de ingresos mínimos y por ayuda de tercera persona se encuentran reguladas en la DT única del Real Decreto Legislativo 1/2013, de 29 de noviembre, por el que se aprueba el Texto Refundido de la Ley General de derechos de las personas con discapacidad y de su inclusión social (en lo sucesivo TRLGDPD). El subsidio de garantía de ingresos mínimos y por ayuda de tercera persona quedó suprimido por la DT undécima del Real Decreto Legislativo 1/1994, por el que se aprueba el Texto Refundido de la Ley General de la Seguridad Social, manteniendo el derecho las personas beneficiarias que los tenían reconocidos, en los términos y condiciones previstos en la legislación específica que los regulan ${ }^{31}$. Actualmente, las personas beneficiarias que mantienen esos derechos continúan cumpliendo con los requisitos reglamentariamente establecidos. Lógicamente tal y como está configurado el IMV, no como renta universal, existe una fuerte incompatible con el desarrollo de trabajo tanto por cuenta ajena como por cuenta propia, dando lugar a la suspensión del derecho, aunque se fije una recuperación automáticamente cuando se extinga el contrato de trabajo o dejen de realizar actividad laboral.

En la actualidad nos encontramos, tal y como viene reconociendo la doctrina ${ }^{32}$ y la jurisprudencia mayoritaria ${ }^{33}$, ante un régimen de compatibilidades e incompatibilidades que crea ciertas disfunciones y desigualdades de trato entre las personas perceptoras y que, a nuestro juicio, ha sido objeto de una extensa e intensa interpretación jurisprudencial, lo que contrasta, sin embargo, con un escaso interés por parte de la doctrina iuslaboralista.

La doctrina ${ }^{34}$ ha venido señalando tres cuestiones importantes y preliminares en el desarrollo de sistema general de compatibilidad de prestaciones de Seguridad Social y trabajo.

En primer lugar, el principio de prestación única tiene un evidente interés doctrinal, pero no se traduce en un criterio positivo de ordenación general del régimen jurídico de las prestaciones de Seguridad Social, puesto que el ordenamiento no contiene reglas de incompatibilidad de prestaciones de alcance general para todo el Sistema, ni entre éste y los anteriores seguros sociales, por cuanto que el genérico artículo 163 TRLGSS, y la

\footnotetext{
${ }^{31}$ Véase al respecto la Disposición Transitoria Vigésima Quinta en su apartado primero del Real Decreto Legislativo 8/2015, de 30 de octubre, por el que se aprueba el texto refundido de la Ley General de la Seguridad Social.

${ }^{32}$ Por todos, ROMERo RóDENAS, María José, La compatibilidad del trabajo con las prestaciones de Seguridad Social, Albacete, Bomarzo, 2019, p. 11 y ss.

${ }^{33}$ Vid. STS 15 de julio de 2010, rec. 4445/2009, STS 14 de julio de 2014, rec. 338/2013.

${ }^{34}$ Por todos, Romero RóDEnAS, María José, La compatibilidad del trabajo con las prestaciones de Seguridad Social, op. cit., p. 11.
} 
regulación análoga de los regímenes especiales son normas internas de cada régimen, de prácticamente cada regulación legal por lo que resulta su conocimiento harto complicado.

En segundo lugar, resulta pacífico pero creemos que obsoleto que "la regla general de incompatibilidad de pensiones es acorde con el principio de que la pérdida de una renta profesional no puede protegerse a la vez con la percepción de dos prestaciones que tengan la misma finalidad de sustitución, porque en ese caso la renta de sustitución podría ser superior a la sustituida", siquiera lo "jurídicamente correcto" sería en tal supuesto reconocer la "nueva pensión" y permitir que el asegurado "ejercite el derecho de opción" que le atribuye el artículo 163 del TRLGSS" 35 , o establecer criterios no tanto sustantivos (como hasta ahora) como criterios de límites de rentas entre las personas beneficiarias sobre todo pensando en las personas con discapacidad que pueden compatibilizar este tipo de prestaciones con la realización de un trabajo en pleno avance con modelos de ciudadanía inclusiva y modelos de salario social adecuados al marco normativa supraestatal señalado en el inicio de este estudio.

El IMV es diseñado con una férrea incompatibilidad con otras prestaciones públicas de la misma naturaleza o similar a lo que se une la panoplia de mecanismos, ayudas, subsidios protectores autonómicos y locales con mismos ámbitos subjetivos, que en ocasiones han sido interpretados como excluyentes del IMV lo que ha motivado a algunas CCAA de forma precipitada y sin argumentos legales de exclusión a reducir o extinguir sus ayudas a la pobreza y exclusión social ${ }^{36}$ de forma automática sin conocer la verdadera finalidad de protección, inclusión e igualdad que ampara el TRLGDPD en sintonía con la Convención sobre los Derechos de las Personas con Discapacidad ${ }^{37}$.

\footnotetext{
35 Por todos, Mercader Uguina, Jesús (Dir.): La compatibilidad de las prestaciones del Sistema de Seguridad Social, Lex Nova, Pamplona, 2013, p. 23; CABEZA PEREIRO, Jaime, "La incompatibilidad del trabajo con la pensión de jubilación total", en La Seguridad Social a la luz de sus reformas pasadas, presentes y futuras, (Coord. Monereo, Molina y Moreno), libro Homenaje al profesor José Vida Soria, Comares, Granada, 2008, p. 434; GALA DURÁN Carolina, "La compatibilidad entre trabajo y pensión de jubilación y su repercusión en el sector público”, Revista la Administración práctica: enciclopedia de administración municipal n 8 (2013), p. 37 a 44; GALA DURÁN Carolina, "la compatibilidad entre el trabajo y la percepción de las pensiones por incapacidad permanente total, absoluta y gran invalidez tras la ley 27/201, Revista Temas Laborales n 122 (2013), p. 79 a 123. SSTS 19 de diciembre 2000, rec. 4635/99; 22 de mayo de 2001, rec. 2613/2000; 9 de julio de 2001, rec. 3432/00; 18 de diciembre de 2002, rec. 173/2002; 18 de julio de 20023, rec. 2924/02 y 5 de febrero de 2008, rec. 462/2007, etc.

${ }^{36}$ El Ingreso Mínimo de Solidaridad (IMS), la 'renta mínima' castellanomanchega, con una antigüedad de 25 años es sustituida de forma parcial por el IMV https://www.eldiario.es/castilla-la-mancha/ingresominimo-vital-sustituye-castilla-mancha-renta-solidaridad-autonomica_1_6287389.html.

${ }^{37}$ Por todos, Vid. De Lorenzo García Rafael, PÉrez Bueno Luis Cayo, Fundamentos del Derecho de la Discapacidad, Aranzadi, Navarra, 2020, p. 51 y ss.
} 
El TRLGDPD al regular la protección social de las personas con discapacidad, en su artículo 8 fija el "sistema especial de prestaciones sociales y económicas para las personas con discapacidad" y en el artículo 48 y siguientes recoge la "protección social" de las personas con discapacidad y sus familias en tanto tienen derecho a unos servicios y prestaciones sociales que atiendan con garantías de suficiencia y sostenibilidad sus necesidades, dirigidos al desarrollo de su personalidad y su inclusión en la comunidad, incrementando su calidad de vida y bienestar social, que identifica con carácter exclusivo con los servicios sociales. Esta regulación, un tanto confusa, ha sido objeto de crítica por parte de la doctrina ${ }^{38}$. Así, la protección social de las personas con discapacidad se configura a través de tres mecanismos: 1) el sistema especial de prestaciones sociales y económicas para las personas con discapacidad que no se encuentran incluidas en el sistema de Seguridad Social; 2) el sistema de Seguridad Social y, por último, 3) los servicios sociales para las personas con discapacidad y sus familias.

Es preciso subrayar de forma curiosa la incongruencia o desconocimiento terminológico que, como regla general, al menos en la modalidad contributiva de protección, no se utiliza el término "discapacidad" sino el de "incapacidad" para el trabajo ${ }^{39}$. En cambio, cuando se trata de prestaciones no contributivas, su existencia está condicionada de forma directa por la valoración de un "grado de discapacidad" o de enfermedad crónica establecido legalmente, que se determina valorando tanto los factores físicos o sensoriales como los factores sociales complementarios mediante la aplicación de los baremos establecidos en el RD 1971/1999, de 23 de diciembre, de procedimiento para el reconocimiento, declaración y calificación del grado de discapacidad. Una razón más para reivindicar el Derecho de la Discapacidad ${ }^{40}$.

\footnotetext{
${ }^{38}$ Vid. BLASCO LAHOZ en relación con el artículo 8 del TRLGDPD critica el olvido de la acción protectora de la Seguridad Social en su modalidad no contributiva, al entender que el artículo 8 sólo se refiere a los discapacitados que por su trabajo pudieran tener protección de la Seguridad Social y, respecto del artículo 48 y ss., apunta que los preceptos se limitan a regular únicamente los servicios sociales y no "las prestaciones sociales" a las que se refiere inicialmente; en BLASCO LAHOZ, José Francisco, "La prestación social de las personas con discapacidad. Las prestaciones de la seguridad social como instrumento para su desarrollo", Revista de Información Laboral n 11, 2018, Ed. Aranzadi, BIB 2018\14008, p. 5.

${ }^{39}$ En este sentido, el artículo 193.1 de la Texto Refundido de la Ley General de Seguridad Social (en adelante TRLGSS), se refiere a reducciones anatómicas o funcionales graves "que disminuyan o anulen su capacidad laboral", criterio admitido por el Tribunal Supremo al interpretar que el concepto de incapacidad permanente está basado en un criterio de capacidad laboral y funcional según las secuelas, físicas o psíquicas (SSTS de 9 de abril y de 13 de junio de 1990).

${ }^{40}$ Vid. PÉRez Bueno, Luis Cayo (Dir.) Hacia un derecho de la discapacidad. Estudios en homenaje al profesor Rafael de Lorenzo, Navarra, Aranzadi, 2009.
} 


\section{Régimen de compatibilidad del IMV con el trabajo}

El artículo 8.4 del RDL 20/2020, 29 de mayo, precisamente con el fin de que la percepción del IMV no desincentive la actividad laboral, será compatible con las rentas del trabajo o la actividad económica por cuenta propia de la persona beneficiaria individual o, en su caso, de uno o varios miembros de la unidad de convivencia en los términos y con los límites que reglamentariamente se establezcan. En estos casos, se establecerán las condiciones en las que la superación en un ejercicio de los límites de rentas establecidos en el artículo8.2 no suponga la pérdida del derecho a la percepción del IMV en el ejercicio siguiente. El artículo 8.4 párrafo segundo señala expresamente que "Este desarrollo reglamentario, en el marco del diálogo con las organizaciones empresariales y sindicales más representativas, prestará especial atención a la participación de las personas con discapacidad y las familias monoparentales".

Así pues, la ordenación legal del IMV establece, con el fin de no desincentivar la participación en el mercado laboral, la compatibilidad de la percepción del IMV con las rentas del trabajo o la actividad económica por cuenta propia de las personas beneficiarias en los términos y con los límites que reglamentariamente se establezcan. Acertada esta opción de compatibilidad ${ }^{41}$ entre la prestación de una actividad laboral y el percibo del IMV para abandonar la idea clásica y antigua de incompatibilidad entre prestación/trabajo, constituyendo una medida especialmente beneficiosa para las personas con discapacidad que en un alto porcentaje son personas trabajadoras pobres cuyos salarios y dedicaciones parciales voluntarias o involuntarias figurando en la mayoría de los supuestos en los umbrales mínimos de rentas del trabajo. Además, la compatibilidad del trabajo con la percepción del IMV permite no sólo la incorporación al mercado de trabajo sino también fomenta el trabajo como derecho de integración social (artículo 35.1 CE), lo cual se sitúa en una lógica garantista de doble "activación objetiva" ${ }^{42}$, dirigida no solo a evitar la exclusión social sino también prevenir el riesgo de pobreza.

El IMV actúa como una imprescindible herramienta para facilitar la transición de las personas desde la exclusión social impuesta por la carencia de recursos hacia una situación en la que se puedan desarrollar con plenitud en la sociedad eliminando, paliando, evitando y previniendo el riesgo de pobreza. Aunque el origen de la privación económica que sufren las personas con discapacidad se encuentra en su situación de

\footnotetext{
${ }^{41}$ Misma opinión en GALA DURÁN, Carolina "El nuevo ingreso mínimo vital estatal: régimen jurídico y retos pendientes", Revista Trabajo, Persona, Derecho, Mercado n 1 (2020), p. 126.

${ }^{42}$ Monereo PÉREZ, José Luis, "La renta mínima garantizada como medida estructural del sistema de Seguridad Social en la «Sociedad del riesgo»", Revista jurídica de los Derechos Sociales Lex Social, Vol. $10, \mathrm{n}^{\circ} 2,2020$, p. 484.
} 
vulnerabilidad social, la forma concreta que tomara su inclusión social variara en función de las características de cada persona: para algunos, será el acceso a oportunidades educativas, formativas, para otros, la incorporación al mercado de trabajo o, la solución a una condición inclusiva universal favoreciendo así el derecho a la discapacidad ${ }^{43}$. Este objetivo de inclusión condiciona de manera central el diseño de la prestación. Pues, a través de él se introduce un sistema de incentivos que busca evitar la generación de lo que lo expertos en política social han denominado "trampas de pobreza", esto es, que la mera existencia de prestación inhiba el objetivo de inclusión social y económica de los preceptores. Habrá que esperar al desarrollo reglamentario anunciado en el artículo 8.2 RDL 20/2020, de 29 de mayo que deberá de recoger la compatibilidad entre IMV y trabajo con fórmulas flexibles que permita a las personas con discapacidad su integración o permanencia en el mercado laboral con el percibo de esta prestación junto con mecanismos de control del límite de gastos y eventuales fórmulas de trabajo no típicas ${ }^{44}$.

Para la aplicación de este sistema de incentivos, resulta esencial la cooperación con las Comunidades Autónomas y Entidades Locales en el despliegue de unos itinerarios de inclusión flexibles y adaptados a cada situación para las personas beneficiarias del IMV, dado que, en el ejercicio de sus competencias, pueden acceder de manera más directa a las realidades concretas de los perceptores a través de los servicios sociales, pieza clave en la articulación del sistema. El sector privado también será coparticipe del diseño de estos itinerarios de inclusión, estableciéndose un Sello de Inclusión Social que acredite a todas aquellas empresas que ofrezcan oportunidades de empleo y formación a los preceptores del IMV. La centralidad del objetivo de inclusión exigirá que los efectos de la prestación tendrán que ser permanente y rigurosamente evaluados una vez sea puesta en marcha. Al respecto, se prevé la creación de una Comisión de seguimiento del IMV, como órgano de cooperación con las CCAA y entidades locales en materia de inclusión y de un Consejo consultivo, como órgano de consulta y participación con las entidades del Tercer Sector de Acción Social y las organizaciones sindicales y empresariales. Con

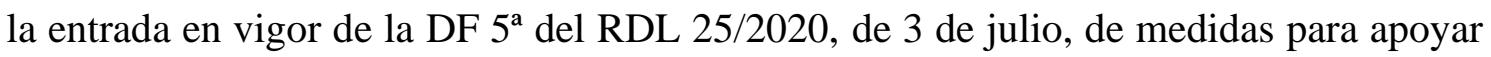
la reactivación económica y el empleo que incorpora el apartado $4^{\circ}$ al artículo 20 del RDL 20/2020, de 29 de mayo, dando cobertura legal al INSS para facilitar a las CCAA y entidades locales la información necesaria para el reconocimiento y control de las prestaciones que son de su competencia y agilizar la comunicación de las

\footnotetext{
${ }^{43}$ Interesantes las aportaciones de TORRES MARTínEZ, Josefa, "Hacia una nueva Ley Promoción de la Inserción Laboral de las Personas con Discapacidad", en Avanzando en la inclusión. Balance de logros alcanzados y agenda pendiente en el derecho español de la discapacidad, (Dir. MARTINEZ-PUJALTE, Antonio Luis, Miranda ERro, Javier Coord. FloreS, Myriam), Navarra, Aranzadi, 2019, p. 159-172.

${ }^{44}$ Eventuales trabajos en la economía sumergida "Arbitrar mecanismos eficaces para evitar este y otros tipos de fraude que puedan darse en el marco del IMV" en GaLA DuRÁN, Carolina "El nuevo ingreso mínimo vital estatal: régimen jurídico y retos pendientes", Revista Trabajo, Persona, Derecho... op.cit. p. 127.
} 
administraciones para la gestión y control del ingreso mínimo vital. Asimismo, se habilita la transmisión de información entre el INSS y las Haciendas Forales en idénticos términos.

\section{Régimen de incompatibilidad del IMV}

La percepción del IMV es incompatible con la percepción de la asignación económica por hijo o menor a cargo, sin discapacidad o con discapacidad inferior al 33 por ciento, cuando exista identidad de causantes o beneficiarios de esta (artículo 16 RDL 20/2020 modificado por RDL 30/2020). En función de la cuantía, se establece que se reconocerá el derecho al IMV si este es superior lo cual extinguirá el derecho a la asignación por hijo o menor a cargo. En cambio, si la cuantía del IMV es inferior o la persona interesada optará por el IMV su reconocimiento extinguirá el derecho a la asignación económica por hijo o menor a cargo. Si la persona interesada optara por la asignación económica por hijo o menor a cargo se denegará por esta causa la solicitud de la prestación de renta mínima vital.

En este sentido, la DT $7^{\text {a }}$ RDL 20/2020, de 29 de mayo, dispone la integración de la asignación por hijo o menor a cargo al IMV. Los beneficiarios de la asignación económica por cada hijo o menor a cargo sin discapacidad o con discapacidad inferior al 33 por ciento continuarán percibiendo dicha prestación hasta que deje de concurrir los requisitos y proceda su extinción.

Se establece un régimen transitorio no pacífico en la DT.1 RDL 20/2020, 29 de mayo, que ya ha sido objeto de modificaciones por el RDL 25/2020, de 3 de julio y RDL 28/2020, de 22 de septiembre. En este sentido, el INSS ha reconocido durante el año 2020 la prestación transitoria de ingreso mínimo vital a los beneficiarios de la asignación económica por hijo o menor a cargo del sistema de la Seguridad Social que, a fecha de entrada en vigor del RDL 20/2020, 29 de mayo, reunieran ciertos requisitos, siempre que el importe de la prestación transitoria de ingreso mínimo vital sea igual o superior al importe de la asignación económica que viniera percibiendo.

Los requisitos para percibir la prestación transitoria están muy limitados ${ }^{45}$ y tras la nueva redacción dada por el RDL 28/2020, de 22 de septiembre el INSS reconocerá de oficio la

\footnotetext{
${ }^{45}$ Beneficiario de la asignación económica por hijo o menor a cargo sin discapacidad o con discapacidad inferior al 33 por ciento; formar parte de una unidad de convivencia constituida exclusivamente por el beneficiario de una asignación económica por hijo o menor a cargo sin discapacidad o con discapacidad inferior al 33 por ciento, el otro progenitor en caso de convivencia, y los hijos o menores a cargo causantes de dicha asignación por hijo a cargo; encontrarse la unidad de convivencia en situación de vulnerabilidad
} 
prestación transitoria de IMV, cuando concurran los siguientes requisitos: ser beneficiario de la asignación económica por hijo o menor a cargo sin discapacidad o con discapacidad inferior al 33 por ciento; cuando el número total de convivientes que consta en las bases de datos de población disponible que el INE cede periódicamente a dicha AEAT para fines de estudio y análisis, sea mayor que el número de integrantes de la unidad de convivencia, ésta estará constituida únicamente por el beneficiario de una asignación económica por hijo o menor a cargo sin discapacidad o con discapacidad inferior al 33 por ciento, el otro progenitor en caso de convivencia, y los hijos o menores a cargo causantes de dicha asignación por hijo a cargo; encontrarse la unidad de convivencia referida en el apartado anterior, en situación de vulnerabilidad económica por carecer de patrimonio, rentas o ingresos suficientes (artículo 8 RDL 20/2020). Siempre que, además, la suma de las rentas e ingresos del total de convivientes no supere la cuantía mensual de la renta garantizada que les correspondería en el caso de que de constituyeran una unidad de convivencia; que la asignación económica por hijo o menor a cargo del sistema de la Seguridad Social que se perciba, o la suma de todas ellas en el supuesto que sean varias las asignaciones, sea inferior al importe de la prestación transitoria.

A partir del 2 de junio 2020 se dejó sin vigor la asignación económica por hijo o menor a cargo sin discapacidad o con discapacidad inferior al 33 por ciento del sistema de la Seguridad Social. Sin embargo, está “derogación” de derecho en la asignación económica por hijo o menor a cargo, no fue una derogación de hecho al mantener un régimen transitorio de aplicación a 31 de diciembre de 2020 cuando se cumplían los requisitos para ser personas beneficiarias del IMV y articular así un mecanismo de derecho de opción para volver a la asignación económica por hijo o menor a cargo del sistema de la Seguridad Social. Un laberinto normativo difícil de gestionar en la práctica como hemos visto.

Otra incompatibilidad con el IMV a nuestro juicio poco estudiada por el legislador, lo constituye la prestación de servicio residencial, de carácter social, sanitario o sociosanitario, con carácter permanente y financiada con fondos públicos. Desde movimientos asociativos se ha criticado duramente la exclusión de las prestaciones residenciales y el IMV. Un estudio de la Asociación Española de Fundaciones Tutelares señaló que el 80 por ciento de sus tutelados viven en residencias y que el 70 por ciento de estos se encuentran en situación de pobreza, por tanto, consideramos que esta incompatibilidad debería de ser más analizada en consonancia con el objeto constitutivo del IMV.

económica; que la asignación económica que se perciba, o la suma de todas ellas en el supuesto que sean varias las asignaciones, sea inferior al importe de la prestación de la renta mínima vital. 


\section{El encaje del IMV con otras prestaciones públicas estatales y autonómicas}

Entre rentas mínimas estatales ya existentes destacamos el subsidio por desempleo y la renta activa de inserción (RAI). Estas rentas mínimas, a diferencia del IMV, están dirigidos a colectivos concretos, como personas de una determinada edad (más de 45 o 55 años), personas con responsabilidades familiares o con especiales necesidades de inserción. En cambio, el IMV ha ampliado considerablemente el ámbito subjetivo de protección ya que no se dirige solamente a un determinado colectivo, sino que se dirige a la sociedad en su conjunto, permitiendo el acceso a la misma a aquellas personas que incluso teniendo ingresos los mismos no son suficientes para satisfacer sus necesidades básicas.

El IMV tiene una duración indefinida, esto es, su percepción económica se mantiene mientras se cumplan los requisitos y las obligaciones establecidas. No obstante, es necesario matizar que el IMV tiene un carácter complementario de otras rentas, de modo que su cuantía final podría ser inferior a la fijada en el RDL 20/2020, de 29 de mayo, importante diferencia que no sucede con el resto de prestaciones, cuya cuantía se obtiene íntegramente si se cumplen los requisitos exigidos.

El IMV, como hemos puesto de manifiesto, tiene como objetivo remediar, prevenir situaciones de pobreza y exclusión social con ayudas económicas asociadas a medidas de inclusión laboral. Dado el objetivo común con otras prestaciones, la entrada en vigor del IMV, evidenció una situación de solapamiento parcial de protección lo que cuestionó y puso en duda la vigencia de la panoplia de prestaciones existentes con los mismos o parecidos fines. Aunque el RDL 20/2020, 29 de mayo omite referencia alguna a las prestaciones de carácter estatal, se podría entender que el IMV es compatible con el resto de prestaciones públicas estatales, pero, como señala la Exposición de Motivos del RDL 20/2020, de 29 de mayo, es necesaria una futura reordenación del conjunto de ayudas estatales cuyos objetivos se solapen con los de este nuevo instrumento y se establezca un marco regulador más definido, integrador e inclusivo del conjunto de prestaciones a las personas discapacitadas, se echa en falta un verdadero marco regulador del derecho a la protección social de las personas discapacitadas. Y en este sentido, la propia Exposición de Motivos al subrayar que el IMV "se configura como una prestación «suelo» que se hace compatible con las prestaciones autonómicas que las comunidades autónomas, en el ejercicio de sus competencias estatutarias, puedan conceder en concepto de rentas mínimas, tanto en términos de cobertura como de generosidad", nos recuerda que el IMV actúa como «suelo» general contra la pobreza y exclusión social, ya que, a los efectos de determinar los requisitos relativos al cómputo de los ingresos para determinar el grado de vulnerabilidad económica de las personas beneficiarias individual o de la unidad familiar, se exige por la norma de forma muy acertada que no serán computables "los salarios 
sociales, las rentas mínimas de inserción o ayudas análogas de asistencia social concedidas por las Comunidades Autónomas". Con ello, la voluntad política del legislador ha querido diseñar un IMV, como "suelo común" de renta mínima", respetando el margen de actuación de las políticas sociales de cada Comunidad Autónoma.

Finalmente, la configuración del IMV como suelo de protección general y claramente compatible con las rentas mínimas autonómicas tiene por objeto llegar a un mayor número de personas que se encuentran en situación de vulnerabilidad económica, tratando de simplificar el proceso de solicitud (aunque no tanto su gestión) y mejorar la cobertura en su cuantía. No obstante, la indudable mejora de lo que supone el IMV a nivel de protección estatal, lo que cabe preguntarnos es cómo afectará el IMV a la actual regulación de las rentas mínimas autonómicas. Se podría entender de la propia Exposición de Motivos que se está invitando a las CCAA a repensar sus modelos de rentas mínimas para que puedan complementar a la estatal "tanto en términos de cobertura como de generosidad" 47 , no muy respetada por algunas CCAA. El futuro desarrollo reglamentario del IMV debe incidir también en esta cuestión, en el nivel de ingresos mínimos garantizados por el Gobierno a nivel nacional, para que las CCAA puedan complementarla en función de las peculiaridades de su territorio, pero no estableciendo diferencias territoriales que impliquen desigualdades económicas y sociales en función de territorio o ámbito geográfico concreto en el que se residan las personas necesitadas.

\section{Bibliografía}

APARICIO TOVAR, Joaquín., "La sostenibilidad como excusa para una reestructuración del sistema de la Seguridad Social”, Cuadernos de Relaciones Laborales, Vol. 33, nº 2, 2015.

ARRIETA IDIÁKEZ, Francisco Javier, "Ingreso Mínimo Vital: compatibilidades e incompatibilidades," en https://forodelabos.blogspot.com/ (20/7/2020).

BLASCO LAHOZ, José Francisco, "La prestación social de las personas con discapacidad. Las prestaciones de la seguridad social como instrumento para su desarrollo", Revista de Información Laboral nº 11, 2018, Ed. Aranzadi, BIB $2018 \backslash 14008$.

CABEZA PEREIRo, Jaime, "La incompatibilidad del trabajo con la pensión de jubilación total", en La Seguridad Social a la luz de sus reformas pasadas, presentes y futuras,

\footnotetext{
${ }^{46}$ Ramos QuinTANA, Margarita Isabel, "El ingreso mínimo vital como instrumento para combatir la pobreza y la exclusión desde el sistema de la Seguridad Social", op.cit., p. 316.

${ }^{47}$ SAla Franco, Tomás., MARTín-POZUElo LóPEZ, Ángela, El Ingreso Mínimo Vital. El Sistema Español de Rentas Mínimas, op. cit., p. 148.
} 
(Coord. Monereo, Molina y Moreno), libro Homenaje al profesor José Vida Soria, Comares, Granada, 2008.

De Lorenzo García, Rafael, Pérez Bueno, Luis Cayo, Fundamentos del Derecho de la Discapacidad, Navarra, Aranzadi, 2020.

FERRAJOLI, Luigi, Manifiesto por la igualdad, Madrid, Trotta, 2019.

Gala DURÁn, Carolina "La compatibilidad entre trabajo y pensión de jubilación y su repercusión en el sector público”, Revista la Administración práctica: enciclopedia de administración municipal, $\mathrm{n}^{\circ}$ 8, 2013.

GALA DURÁn, Carolina, "El nuevo ingreso mínimo vital estatal: régimen jurídico y retos pendiente", Revista Trabajo, Persona, Derecho, Mercado, nº 1, 2020.

Gala Durán, Carolina, "La compatibilidad entre el trabajo y la percepción de las pensiones por incapacidad permanente total, absoluta y gran invalidez tras la ley 27/2011, Revista Temas Laborales $\mathrm{n}^{\mathrm{o}} 122$ (2013).

Gala DURÁN, Carolina, "Los desafíos del nuevo ingreso mínimo vital", IUSLabor. Revista d'anàlisi de Dret del Treball, $\mathrm{n}^{\mathrm{o}}$ 2, 2020.

GonzÁlez OrTEga, Santiago y B ARCElón CoBedo, Susana, Introducción al Derecho de la Seguridad Social, Valencia, Tirant lo Blanch, 2020.

Legarreta Esteban, Ricardo, "La renta básica universal", en VV.AA., "Políticas sociolaborales", CARDONA Rubert, María Belén, (coord.), CABEZA PEREIRO, Jaime, (coord.), Navarra, Ed. Thomson Reuters-Civitas, 2014.

MERCADER Uguina, Jesús (Dir.): La compatibilidad de las prestaciones del Sistema de Seguridad Social, Pamplona, Lex Nova, 2013.

Monereo Pérez, José Luis y Rodriguez InIESTA, Guillermo, "El derecho social fundamental a la existencia digna y el Ingreso Mínimo Vital", Revista de Derecho de la Seguridad Social, $\mathrm{n}^{\circ}$ 24, 3er Trimestre, 2020.

Monereo PÉrez, José Luis, "El derecho a la Seguridad Social (Artículo 41 y concordantes)", en VV.AA., Comentario a la Constitución Socio-Económica de España, Monereo Pérez, José Luis, Molina Navarrete, Cristóbal y Moreno VidA, María Nieves. (Dirs. y Coords.), Granada, Ed. Comares, 2002. 
Monereo PÉreZ, José Luis, "La renta mínima garantizada como medida estructural del sistema de Seguridad Social en la «Sociedad del riesgo»", Revista jurídica de los Derechos Sociales Lex Social, Vol. 10, n 2, 2020.

PÉRez Bueno Luis Cayo, (Dir.) Hacia un derecho de la discapacidad. Estudios en homenaje al profesor Rafael de Lorenzo, Navarra, Aranzadi, 2009.

RAmos QuintanA, Margarita Isabel, "El ingreso mínimo vital como instrumento para combatir la pobreza y la exclusión desde el sistema de la Seguridad Social”, Revista Hacienda Canaria, $\mathrm{n}^{\circ}$ 53, 2020.

Romero RódenAs, María José, La compatibilidad del trabajo con las prestaciones de Seguridad Social, Albacete, Bomarzo, 2019.

Sala Franco, Tomás, Martín-POzuelo LóPez, Ángela, El Ingreso Mínimo Vital. El Sistema Español de Rentas Minimas, Valencia, Ed. Tirant Lo Blanch, 2020.

Torres MArtínez Josefa, "Hacia una nueva Ley Promoción de la Inserción Laboral de las Personas con Discapacidad", en Avanzando en la inclusión. Balance de logros alcanzados y agenda pendiente en el derecho español de la discapacidad, (Dir. Martinez-Pujalte, Antonio-Luis, Miranda Erro, Javier, Coord. Flores, Myriam.), Navarra, Aranzadi, 2019. 